\title{
Non-Exercise Based Estimation of Cardiorespiratory Fitness Mediates Associations between Comorbidities and Health-Related Quality of Life in Older Korean Adults with Diabetes
}

\author{
Inhwan Lee ${ }^{1}$, Shinuk Kim ${ }^{2}$ and Hyunsik Kang ${ }^{1, *(1)}$ \\ 1 College of Sport Science, Sungkyunkwan University, Suwon 16419, Korea; ansh00@skku.edu \\ 2 College of Kyedang General Education, Sangmyung University, Cheonan 31066, Korea; kshinuk@gmail.com \\ * Correspondence: hkang@skku.edu; Tel.: +82-31-299-6911
}

Received: 14 December 2019; Accepted: 8 February 2020; Published: 12 February 2020

check for updates

\begin{abstract}
This study investigated whether non-exercise-based estimation of cardiorespiratory fitness (eCRF) mediates the association between health-related quality of life (HRQoL) and comorbidities in older Korean adults with diabetes. A total of 1371 Korean adults ( $56 \%$ women) aged 60 years and older with diabetes was drawn from those who participated in the 2008-2011 Korea National Health and Nutrition Examination Surveys IV and V. Data on comorbidities included hypertension, heart disease (acute myocardial infarction or angina), stroke, arthritis, and chronic renal disease. HRQoL was assessed using the EuroQoL group, which consists of a health-status descriptive system and a visual analogue scale. eCRF was determined with sex-specific algorithms. Age, sex, household income, education level, marital status, smoking, alcohol consumption, and regular exercise were additionally measured as covariates. HRQoL found to be inversely associated with number of comorbidities and positively associated with increasing eCRF category (from low to high) in older Korean patients with diabetes. The Sobel mediation test showed a significant indirect effect $(Z=-4.632, p<0.001)$, and the result of a bootstrap procedure corroborated the Sobel test result: a non-zero range in the $95 \%$ bias-corrected confidence interval ( $95 \%$ CI -1.104 to -0.453 ) indicated that eCRF mediates the impact of comorbidities on HRQoL. Overall, the current findings suggest that enhancing CRF can facilitate positive outcomes, including better HRQoL, for patients with diabetes.
\end{abstract}

Keywords: physical fitness; quality of life; chronic diseases; Korean adults

\section{Introduction}

Diabetes represents a clustering of heterogeneous risk factors that affects all aspects of quality of life due to the lifetime demands of diabetes care [1]. Health-related quality of life (HRQoL) refers to a multi-dimensional concept of quality of life, which can be affected by illnesses or treatments. Thus, assessment of HRQoL is an important outcome measure to evaluate overall disease management for patients with diabetes, including disease course, early detection of complications, and effectiveness and efficacy of interventions [2].

Comorbidity is defined as the presence of chronic conditions existing concurrently with a primary disease [3]. Patients with diabetes often have multiple comorbidities, including hypertension, overweight or obesity, hyperlipidemia, chronic kidney disease, and cardiovascular disease, all of which can impact the patient's HRQoL $[4,5]$. Consequently, the management of chronic conditions in patients with diabetes will benefit from a focus on HRQoL.

Cardiorespiratory fitness (CRF), which is defined as the minimum volume of oxygen consumption during a maximal exercise test, has been found to protect against chronic diseases and premature 
death from those diseases [6,7]. For example, higher CRF is associated with lower risks of morbidity and mortality in younger and older adults [8]. Some studies have examined the association between physical activity and HRQoL in healthy persons, as well as those with chronic diseases, reporting positive relationships for both groups $[9,10]$.

Unlike physical activity (PA), less attention has been paid to the relationship between CRF and HRQoL. Although research in this area is limited, the current evidence suggests a positive relationship between CRF and HRQoL in patients with chronic and metabolic diseases [11]. In older persons, however, objectively measuring CRF can be difficult due to the requirements related to its measurement, such as specialized equipment; trained personnel; amount of time, volitional exertion; and mobility. Importantly, studies have found that CRF can be estimated with acceptable accuracy from routinely obtained health indicators $[12,13]$. We have previously shown that non-exercise-based estimation of cardiorespiratory fitness (eCRF) can serve as a prognostic tool for estimating the risk of mortality from all and specific causes in older Korean adults [14].

Nationwide data in South Korea revealed that a majority of patients with diabetes have one or more comorbidities which can affect HRQoL, including obesity, hypertension, hypercholesterolemia, and others [15]. Health behaviors, including PA and CRF, likely mediate the impact of comorbidities on HRQoL among these patients. To the best of our knowledge, however, no previous studies have examined the mediating effect of CRF on the relationships between comorbidities and HRQoL in patients with diabetes in South Korea. Therefore, we investigated whether eCRF mediates the impact of comorbidities on HRQoL in older Korean adults with type-2 diabetes.

\section{Materials and Methods}

\subsection{Study Design and Participants}

The cross-sectional data used for this study were drawn from the Korea National Health and Nutrition Examination Surveys (KNHANES) IV and V, which are nationwide surveys that were conducted from 2008 until 2011 in South Korea. A detailed description of the survey sampling method is available elsewhere [16,17]. For the current study, we initially selected a total of 2757 adults aged 60 years and older from those who participated in the 2008-2011 KNHANES IV and V. We then excluded 1386 individuals because no baseline data were available regarding body composition $(n=352)$, resting heart rate $(n=799)$, PA $(n=17)$, and HRQoL $(n=218)$. Consequently, a total of 1371 older adults with diabetes (604 men; 767 women) were included in the final data analyses. The presence of diabetes was determined with a self-reported questionnaire that asked whether the participants had ever received a diagnosis of diabetes from a physician. The institutional review board of human study reviewed and approved the study protocol participants (SKKU 2017-06-009). Informed consent was obtained from all participants in the study.

\subsection{Study Variables}

\subsubsection{Assessment of HRQoL (Dependent Variable, Y)}

HRQoL was assessed with the EuroQoL group, which consists of a health-status descriptive system (EQ-5D) and a visual analogue scale (EQ-VAS). The EQ-5D records the level of self-reported problems in five dimensions: mobility, self-care, usual activities, pain/discomfort, and anxiety/depression [18,19]. Each of the dimensions is assessed based on a single question with three response levels (no problems, some problems, and extreme problems). Scores on the EQ-5D index range from -0.171 to 1 , where 1 indicates no problems in any of the five dimensions, zero indicates death, and negative values indicate a health status worse than death. Next, patients report their health status with the EQ-VAS, which involves a VAS ranging from 0 (worst imaginable health) to 100 (best imaginable health) [18]. 


\subsubsection{Assessment of Comorbidities (Independent Variable, $X$ )}

Participants were asked if they had ever been diagnosed by a physician with any of the following medical condition(s): malignancy, hypertension, heart disease (acute myocardial infarction or angina), stroke, arthritis, and/or chronic renal disease.

\subsubsection{Estimation of Cardiorespiratory Fitness (Mediator, M)}

Non-exercise-based eCRF was calculated as one-minute peak volume of oxygen consumption $\left(\mathrm{VO}_{2 \text { peak }}\right)$ in units of metabolic equivalents (METs), in accordance with previously reported procedures [13]:

$$
\begin{gathered}
\mathrm{eCRF}(\mathrm{METs})=2.77(\mathrm{sex})-0.10(\text { age })-0.17(\mathrm{BMI})-0.03(\text { resting heart rate }) \\
+1.00(\text { physical activity score })+18.07
\end{gathered}
$$

Once the algorithms were implemented, participants were classified into low (lowest $25 \%$ ), middle (middle 50\%), and high (highest 25\%) categories on the basis of sex-specific tertiles of the estimated peak $\mathrm{VO}_{2}$ distributions.

\subsubsection{Covariates}

Measured covariates included age, sex, household income, education level (lower than elementary school, middle/high school, or college or higher), marital status (yes or no), current smoker (never or past/current), frequency of alcohol consumption (more or less than twice per week), and regular exercise (yes or no).

\subsection{Statistical Analyses}

All variables were checked for normality, both visually and through the Kolmogorov-Smirnov test, and subjected to an appropriate transformation, if necessary, prior to statistical analyses. Descriptive statistics are presented as means and standard deviations for continuous variables and as frequencies and percentages for categorical variables. Analysis of variance (ANOVA) was used to test linear trends in outcome variables according to number of comorbidities and eCRF categories.

We examined the relationships between number of comorbidities, eCRF, and HRQoL using parametric and non-parametric statistics. Then, the impact of comorbidities on HRQoL through eCRF was tested based on four criteria for the mediation paths proposed by Baron and Kenny [20], as illustrated in Figure 1: (1) the coefficient of path "a" is significant in identifying the effect of the independent variable (IV) on the mediating variable (MV); (2) the MV is significantly related to the dependent variable (DV) of the IV (path b); (3) a significant direct association (path c) between the IV and DV is confirmed; and (4) the association between the IV and DV is weakened when the MV is controlled (path $c^{\prime}$ ). The PROCESS macro in SPSS-PC (version 23.0, IBM Corporation, Armonk, NY, USA) was used to carry out the mediation analyses. No covariates were included in Model 1, demographics and socio-economic status (SES) variables were included in Model 2, and variables of health behaviors were added to Model 3. The possible mediating effect of eCRF on the impact of comorbidities on HRQoL was identified using the Sobel mediation test with a bootstrapping process, which overcomes the assumption of a normal distribution of the classical Sobel mediation test. The robustness of $p$-values was confirmed via the bootstrapping process. An $\alpha$ level of 0.05 was used for all statistical analyses. 


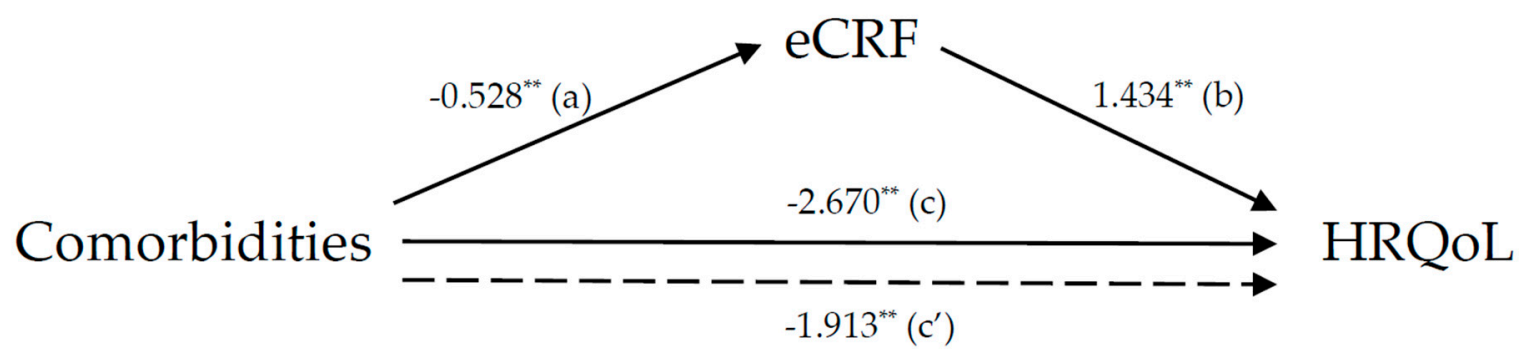

Figure 1. Mediation analysis. Path coefficients of comorbidities on health-related quality of life (HRQoL) through non-exercise based estimation of cardiorespiratory fitness (eCRF). ${ }^{* *}$ indicates statistical significance at $p<0.001$ for all the paths.

\section{Results}

Table 1 summarizes descriptive statistics of participants. Overall, male participants were older $(p<0.001)$, heavier $(p<0.001)$, more educated $(p<0.001)$, and less likely to be alone $(p<0.001)$ than female participants. Men had higher values for smoking $(p<0.001)$ and alcohol intake $(p<0.001)$, but lower values for resting heart rate $(p=0.023)$ and number of comorbidities $(p<0.001)$ than women. Men were less physically active $(p<0.001)$ but had higher values on the EQ-5D index $(p<0.001)$ and EQ-VAS $(p<0.001)$ than women. We found no significant differences in marital status or income between older men and women.

Table 1. Descriptive statistics of study participants (Mean \pm SD).

\begin{tabular}{|c|c|c|c|c|}
\hline Variables & $\begin{array}{c}\text { All } \\
(n=1371)\end{array}$ & $\begin{array}{c}\text { Men } \\
(n=604)\end{array}$ & $\begin{array}{l}\text { Women } \\
(n=767)\end{array}$ & $p$-Value \\
\hline \multicolumn{5}{|l|}{ Demographics } \\
\hline Age (years) & $69.1 \pm 6.1$ & $68.3 \pm 5.9$ & $69.8 \pm 6.2$ & $<0.001$ \\
\hline Marital status, $n(\%)$ & & & & 0.606 \\
\hline Yes & $1360(99.2)$ & $600(99.3)$ & $760(99.1)$ & \\
\hline No & $11(0.8)$ & $4(0.7)$ & $7(0.9)$ & \\
\hline Living condition, $n(\%)$ & & & & $<0.001$ \\
\hline Live someone & $1176(85.8)$ & $564(93.4)$ & $612(79.8)$ & \\
\hline Alone & $195(14.2)$ & $40(6.6)$ & $155(20.2)$ & \\
\hline \multicolumn{5}{|l|}{ Socioeconomic Status } \\
\hline Income (10,000 won/month) & $228.1 \pm 113.0$ & $217.1 \pm 319.9$ & $236.8 \pm 148.6$ & 0.752 \\
\hline Education, $n(\%)$ & & & & $<0.001$ \\
\hline Lower than elementary school & $558(40.7)$ & $122(20.2)$ & $436(56.8)$ & \\
\hline Middle/high school & $597(43.5)$ & $304(50.3)$ & $293(38.2)$ & \\
\hline Over than college & $216(15.8)$ & $178(29.5)$ & $38(5.0)$ & \\
\hline Health Behavior Factors & & & & $<0.001$ \\
\hline \multicolumn{5}{|l|}{ Smoking, $n(\%)$} \\
\hline Never & $769(56.1)$ & $87(14.4)$ & $682(88.9)$ & \\
\hline Past/current & $602(43.9)$ & $517(85.6)$ & $85(11.1)$ & \\
\hline Weekly alcohol intake, $n(\%)$ & & & & $<0.001$ \\
\hline$<2$ & $1137(82.9)$ & $394(65.2)$ & $743(96.9)$ & \\
\hline$\geq 2$ & $234(17.1)$ & $210(34.8)$ & $24(3.1)$ & \\
\hline Regular exercise, $n(\%)$ & & & & $<0.001$ \\
\hline Yes & $430(31.4)$ & $243(40.2)$ & $187(24.4)$ & \\
\hline No & $941(68.6)$ & $361(59.8)$ & $580(75.6)$ & \\
\hline Number of Comorbidity, $n(\%)$ & & & & $<0.001$ \\
\hline 0 & $220(16.0)$ & $133(22.0)$ & $87(11.3)$ & \\
\hline 1 & $567(41.4)$ & $286(47.4)$ & $281(36.6)$ & \\
\hline$\geq 2$ & $584(42.6)$ & $185(30.6)$ & $399(52.1)$ & \\
\hline
\end{tabular}


Table 1. Cont.

\begin{tabular}{|c|c|c|c|c|}
\hline Variables & $\begin{array}{c}\text { All } \\
(n=1371)\end{array}$ & $\begin{array}{c}\text { Men } \\
(n=604)\end{array}$ & $\begin{array}{c}\text { Women } \\
(n=767)\end{array}$ & $p$-Value \\
\hline \multicolumn{5}{|l|}{ eCRF Variables } \\
\hline eCRF (METs) & $7.1 \pm 2.3$ & $9.1 \pm 1.6$ & $5.6 \pm 1.5$ & $<0.001$ \\
\hline $\operatorname{BMI}\left(\mathrm{kg} / \mathrm{m}^{2}\right)$ & $24.7 \pm 3.3$ & $24.0 \pm 3.0$ & $25.3 \pm 3.5$ & $<0.001$ \\
\hline RHR (beats/min) & $73.0 \pm 10.2$ & $72.3 \pm 10.5$ & $73.5 \pm 9.8$ & 0.023 \\
\hline Physical activity score, $n(\%)$ & & & & $<0.001$ \\
\hline Level 1 & $224(16.3)$ & $66(10.9)$ & $158(20.6)$ & \\
\hline Level 2 & $642(46.9)$ & $283(46.9)$ & $359(46.8)$ & \\
\hline Level 3 & $23(1.7)$ & $8(1.3)$ & $15(2.0)$ & \\
\hline Level 4 & $95(6.9)$ & $40(6.6)$ & $55(7.2)$ & \\
\hline Level 5 & $387(28.2)$ & $207(34.3)$ & $180(23.4)$ & \\
\hline \multicolumn{5}{|l|}{ Health-Related Quality of Life } \\
\hline \multicolumn{5}{|l|}{ EQ-5D problems } \\
\hline Mobility, $n(\%)$ & $621(45.3)$ & $189(31.3)$ & $432(56.3)$ & $<0.001$ \\
\hline Self-care, $n(\%)$ & $205(15.0)$ & $55(9.1)$ & $150(19.6)$ & $<0.001$ \\
\hline Usual activities, $n(\%)$ & 409 (29.8) & $121(20.0)$ & $288(37.5)$ & $<0.001$ \\
\hline Pain/discomfort, $n(\%)$ & $585(42.7)$ & 189 (31.3) & $396(51.6)$ & $<0.001$ \\
\hline Anxiety/depression, $n(\%)$ & $260(19.0)$ & $79(13.1)$ & $181(23.6)$ & $<0.001$ \\
\hline EQ-5D index & $0.85 \pm 0.18$ & $0.90 \pm 0.15$ & $0.81 \pm 0.19$ & $<0.001$ \\
\hline EQ-VAS score & $67.0 \pm 22.1$ & $70.1 \pm 19.0$ & $64.6 \pm 24.0$ & $<0.001$ \\
\hline
\end{tabular}

Table 2 compares the measured parameters in relation to number of comorbidities. Significantly, positive, linear trends in mean age $(p<0.001)$, solitary status $(p=0.022)$, and smoking status $(p<0.001)$ and significant, negative linear trends in education $(p=0.001)$, alcohol consumption $(p=0.004), \mathrm{EQ}-5 \mathrm{D}$ index $(p<0.001)$, and EQ-VAS score $(p=0.002)$ were found in relation to the number of comorbidities. In general, patients with one or more comorbidities were older, more likely to live alone, less likely to smoke, consumed alcohol less frequently, and had worse HRQoL than patients with no comorbidities.

Table 2. Comparison of measurement variables according to number of comorbidity (Mean \pm SD).

\begin{tabular}{|c|c|c|c|c|}
\hline \multirow{2}{*}{ Variables } & \multicolumn{3}{|c|}{ Number of Comorbidity } & \multirow{2}{*}{$p$ for Linear Trend } \\
\hline & $0(n=220)$ & $1(n=567)$ & $\geq 2(n=584)$ & \\
\hline \multicolumn{5}{|l|}{ Socio-Demographic Status } \\
\hline Age (years) & $67.6 \pm 6.0$ & $69.3 \pm 6.3$ & $69.6 \pm 5.9$ & $<0.001$ \\
\hline Marital status, $n(\%)$ & & & & 0.194 \\
\hline Yes & $219(99.5)$ & $564(99.5)$ & $577(98.8)$ & \\
\hline $\mathrm{No}$ & $1(0.5)$ & $3(0.5)$ & $7(1.2)$ & \\
\hline Living condition, $n(\%)$ & & & & 0.022 \\
\hline Live someone & $197(89.5)$ & $491(86.6)$ & $488(83.6)$ & \\
\hline Alone & $23(10.5)$ & $76(13.4)$ & $96(16.4)$ & \\
\hline \multicolumn{5}{|l|}{ Socio-Economic Status } \\
\hline Income (10,000 won/month) & $236.5 \pm 386.3$ & $268.0 \pm 172.2$ & $186.8 \pm 289.2$ & 0.583 \\
\hline Education, $n(\%)$ & & & & 0.001 \\
\hline Lower than elementary school & $71(32.3)$ & $234(41.3)$ & $253(43.3)$ & \\
\hline Middle/high school & $106(48.2)$ & $234(41.3)$ & $257(44.0)$ & \\
\hline Over than college & $43(19.5)$ & $99(17.4)$ & $74(12.7)$ & \\
\hline
\end{tabular}


Table 2. Cont.

\begin{tabular}{|c|c|c|c|c|}
\hline \multirow{2}{*}{ Variables } & \multicolumn{3}{|c|}{ Number of Comorbidity } & \multirow{2}{*}{$p$ for Linear Trend } \\
\hline & $0(n=220)$ & $1(n=567)$ & $\geq 2(n=584)$ & \\
\hline \multicolumn{5}{|l|}{ Health Behavior Factor } \\
\hline Smoking, $n(\%)$ & & & & $<0.001$ \\
\hline Never & $102(46.4)$ & $285(50.3)$ & $382(65.4)$ & \\
\hline Past/current & $118(53.6)$ & $282(49.7)$ & $202(34.6)$ & \\
\hline Weekly alcohol intake, $n(\%)$ & & & & 0.004 \\
\hline$<2$ & $181(82.3)$ & $444(78.3)$ & $512(87.7)$ & \\
\hline$\geq 2$ & $39(17.7)$ & $123(21.7)$ & $72(12.3)$ & \\
\hline Regular exercise, $n(\%)$ & & & & 0.251 \\
\hline Yes & $79(35.9)$ & $172(30.3)$ & $179(30.7)$ & \\
\hline No & $141(64.1)$ & $395(69.7)$ & $405(69.3)$ & \\
\hline \multicolumn{5}{|l|}{$H R Q o L$} \\
\hline \multicolumn{5}{|l|}{ EQ-5D problems } \\
\hline Mobility, $n(\%)$ & $69(31.4)$ & $221(39.0)$ & $331(56.7)$ & $<0.001$ \\
\hline Self-care, $n(\%)$ & $24(10.9)$ & $58(10.2)$ & $123(21.1)$ & $<0.001$ \\
\hline Usual activities, $n(\%)$ & $41(18.6)$ & $136(24.0)$ & $232(39.7)$ & $<0.001$ \\
\hline Pain/discomfort, $n(\%)$ & $73(33.2)$ & $209(36.9)$ & $303(51.9)$ & $<0.001$ \\
\hline Anxiety/depression, $n(\%)$ & $33(15.0)$ & $93(16.4)$ & $134(22.9)$ & $<0.001$ \\
\hline EQ-5D index & $0.90 \pm 0.14$ & $0.87 \pm 0.16$ & $0.81 \pm 0.20$ & $<0.001$ \\
\hline EQ-VAS score & $69.2 \pm 22.7$ & $69.4 \pm 20.9$ & $63.9 \pm 22.5$ & 0.002 \\
\hline
\end{tabular}

Table 3 compares the measured parameters according to eCRF category. Significantly, negative linear trends in mean age $(p<0.001)$, solitary status $(p=0.003)$, physical activity $(p<0.001)$, and number of comorbidities $(p=0.008)$ and significant, positive linear trends in education $(p=0.002)$, alcohol consumption $(p=0.034)$, EQ-5D index $(p<0.001)$, and EQ-VAS score $(p<0.001)$ were found in relation to increased eCRF (from low to high). Patients who were physically fit were younger, less likely to live alone, less physically active, had more education, consumed alcohol more frequently, had fewer comorbidities, and had higher values on the EQ-5D index and EQ-VAS than patients who were less physically fit. No significant linear trends in sex, marital status, income, or smoking were found in relation to eCRF category.

Table 3. Descriptive statistics of measured parameters according to eCRF categories (Mean \pm SD).

\begin{tabular}{|c|c|c|c|c|}
\hline \multirow[b]{2}{*}{ Variables } & \multicolumn{3}{|c|}{ eCRF Categories } & \multirow[b]{2}{*}{$p$ for Linear Trend } \\
\hline & $\begin{array}{c}\text { Low } \\
(n=342)\end{array}$ & $\begin{array}{l}\text { Middle } \\
(n=686)\end{array}$ & $\begin{array}{c}\text { High } \\
(n=343)\end{array}$ & \\
\hline eCRF (METs) & $5.3 \pm 1.8$ & $7.0 \pm 1.9$ & $9.3 \pm 1.8$ & $<0.001$ \\
\hline \multicolumn{5}{|l|}{ Demographics } \\
\hline Age (years) & $74.3 \pm 5.5$ & $67.9 \pm 5.3$ & $66.5 \pm 5.2$ & $<0.001$ \\
\hline Marital status, $n(\%)$ & & & & 0.198 \\
\hline Yes & $339(99.1)$ & $678(98.8)$ & $343(100.0)$ & \\
\hline No & $3(0.9)$ & $8(1.2)$ & $0(0.0)$ & \\
\hline Living condition, $n(\%)$ & & & & 0.003 \\
\hline Live someone & $274(80.1)$ & $600(87.5)$ & $302(88.0)$ & \\
\hline Alone & $68(19.9)$ & $86(12.5)$ & $41(12.0)$ & \\
\hline \multicolumn{5}{|l|}{ Socioeconomic Status } \\
\hline Income (10,000 won/month) & $291.4 \pm 220.3$ & $191.7 \pm 253.6$ & $238.0 \pm 418.4$ & 0.547 \\
\hline Education, $n(\%)$ & & & & 0.002 \\
\hline Lower than elementary school & $155(45.3)$ & $288(42.0)$ & $115(33.5)$ & \\
\hline Middle/high school & $144(42.1)$ & $284(41.4)$ & 169 (49.3) & \\
\hline Over than college & $43(12.6)$ & $114(16.6)$ & $59(17.2)$ & \\
\hline
\end{tabular}


Table 3. Cont.

\begin{tabular}{|c|c|c|c|c|}
\hline \multirow[b]{2}{*}{ Variables } & \multicolumn{3}{|c|}{ eCRF Categories } & \multirow[b]{2}{*}{$p$ for Linear Trend } \\
\hline & $\begin{array}{c}\text { Low } \\
(n=342)\end{array}$ & $\begin{array}{l}\text { Middle } \\
(n=686)\end{array}$ & $\begin{array}{c}\text { High } \\
(n=343)\end{array}$ & \\
\hline \multicolumn{5}{|l|}{ Health Behavior Factors } \\
\hline Smoking, $n(\%)$ & & & & 0.676 \\
\hline Never & $186(54.4)$ & $391(57.0)$ & $192(56.0)$ & \\
\hline Past/current & $156(45.6)$ & $295(43.0)$ & $151(44.0)$ & \\
\hline Weekly alcohol intake, $n(\%)$ & & & & 0.034 \\
\hline$<2$ & $301(88.0)$ & $555(80.9)$ & 1.9) & \\
\hline$\geq 2$ & $41(12.0)$ & $131(19.1)$ & $62(18.1)$ & \\
\hline Regular exercise, $n(\%)$ & & & & $<0.001$ \\
\hline Yes & $83(24.3)$ & $216(31.5)$ & $131(38.2)$ & \\
\hline No & $259(75.7)$ & $470(68.5)$ & $212(61.8)$ & \\
\hline Number of Comorbidity, $n(\%)$ & & & & 0.008 \\
\hline 0 & $36(10.5)$ & $115(16.8)$ & $69(20.1)$ & \\
\hline 1 & $156(45.6)$ & $270(39.4)$ & 1.1) & \\
\hline$\geq 2$ & $150(43.9)$ & $301(43.8)$ & $133(38.8)$ & \\
\hline \multicolumn{5}{|l|}{ Health-Related Quality of Life } \\
\hline \multicolumn{5}{|l|}{ EQ-5D problems } \\
\hline Mobility, $n(\%)$ & $206(60.2)$ & $288(42.0)$ & (37.0) 127 & $<0.001$ \\
\hline Self-care, $n(\%)$ & $85(24.9)$ & $85(12.4)$ & $35(10.2)$ & $<0.001$ \\
\hline Usual activities, $n(\%)$ & $141(41.2)$ & $178(25.9)$ & $90(26.2)$ & $<0.001$ \\
\hline Pain/discomfort, $n(\%)$ & $170(49.7)$ & $271(39.5)$ & $144(42.0)$ & 0.041 \\
\hline Anxiety/depression, $n(\%)$ & $64(18.7)$ & $140(20.4)$ & $56(16.3)$ & 0.425 \\
\hline EQ-5D index & $0.80 \pm 0.22$ & $0.87 \pm 0.16$ & $0.87 \pm 0.16$ & $<0.001$ \\
\hline EQ-VAS score & $62.9 \pm 24.9$ & $67.3 \pm 20.9$ & $70.6 \pm 20.7$ & $<0.001$ \\
\hline
\end{tabular}

Table 4 represents the impact of eCRF on the associations between comorbidities and HRQoL. Mediation analysis showed that number of comorbidities had a direct effect on HRQoL independent of eCRF ( $\beta_{c^{\prime}}=-1.913, p<0.005 ; c^{\prime}$ path). However, the number of comorbidities also indirectly affected HRQoL through its effect on eCRF. The number of comorbidities was negatively associated with eCRF $\left(\beta a=-0.528, p<0.001 ; a\right.$ path), and eCRF was positively associated with HRQoL $\left(\beta_{b}=1.434, p<0.001\right.$; $b$ path). Both comorbidity and eCRF remained significant predictors of HRQoL even after adjusting for demographics and SES (i.e., age, marital status, living condition, and education in Model $2\left(\beta_{\mathcal{c}^{\prime}}=-2.327\right.$, $p<0.001 ; c^{\prime}$ path; $\beta_{b}=0.996, p<0.001$; b path, respectively), as well as health behaviors (i.e., smoking, alcohol consumption, and regular exercise) in Model $3\left(\beta_{c^{\prime}}=-2.039, p<0.005 ; c^{\prime}\right.$ path and $\beta_{b}=1.153$, $p<0.005$; b path, respectively).

The mediating effect of eCRF on the impact of comorbidities on HRQoL was further tested using the Sobel mediation test with a bootstrapping procedure (Table 4 and Figure 1). The Sobel mediation test showed a significant indirect effect of eCRF on the impact of comorbidities on HRQoL $(Z=-4.632, p<0.001)$. The results of the bootstrap procedure corroborated those of the Sobel test: the $95 \%$ bias-corrected confidence interval (95\% CI -1.104 to -0.453$)$ was non-zero, indicating that eCRF mediated the relationship between comorbidities and HRQoL (Model 1) and accounted for $28.4 \%$ of the total effect on HRQoL. The Sobel mediation effect of eCRF on the relationship between comorbidities and HRQOL remained significant even after adjusting for demographics and SES in Model $2(Z=-3.004, p=0.001)$, with $16.1 \%$ of the total effect being explained. Likewise, this relationship remained significant after adjustments for Model 2 plus inclusion of parameters for health behaviors in Model $3(Z=-2.753, p=0.005)$, with $12.1 \%$ of the total effect explained. 
Table 4. The association between comorbidity and health related quality of life, mediated by eCRF, in diabetes.

\begin{tabular}{|c|c|c|c|c|c|c|}
\hline \multirow{2}{*}{ Path } & \multicolumn{2}{|c|}{ Model 1} & \multicolumn{2}{|c|}{ Model 2} & \multicolumn{2}{|c|}{ Model 3} \\
\hline & $\beta(\mathrm{SE})$ & $95 \%$ CI & $\beta$ (SE) & $95 \% \mathrm{CI}$ & $\beta$ (SE) & $95 \% \mathrm{CI}$ \\
\hline Comorbidity $\rightarrow$ eCRF, a & $\begin{array}{c}-0.528 \\
(0.063) * *\end{array}$ & $\begin{array}{l}-0.652 \text { to } \\
-0.404\end{array}$ & $\begin{array}{l}-0.388 \\
(0.055)^{* *}\end{array}$ & $\begin{array}{l}-0.495 \text { to } \\
-0.281\end{array}$ & $\begin{array}{l}-0.244 \\
(0.046) * *\end{array}$ & $\begin{array}{c}-0.335 \text { to } \\
-0.154\end{array}$ \\
\hline $\mathrm{eCRF} \rightarrow$ Quality of life, $b$ & $\begin{array}{c}1.434 \\
(0.258)^{* *}\end{array}$ & $\begin{array}{c}0.928 \text { to } \\
1.940\end{array}$ & $\begin{array}{c}0.996 \\
(0.300)^{* *}\end{array}$ & $\begin{array}{c}0.407 \text { to } \\
1.586\end{array}$ & $\begin{array}{c}1.153 \\
(0.358) *\end{array}$ & $\begin{array}{l}0.452 \text { to } \\
1.855\end{array}$ \\
\hline Total effect, c & $\begin{array}{l}-2.670 \\
(0.611)^{* *}\end{array}$ & $\begin{array}{c}-3.868 \text { to } \\
-1.472\end{array}$ & $\begin{array}{l}-2.327 \\
(0.609) * *\end{array}$ & $\begin{array}{c}-3.522 \text { to } \\
-1.133\end{array}$ & $\begin{array}{l}-2.321 \\
(0.613) * *\end{array}$ & $\begin{array}{c}-3.522 \text { to } \\
-1.119\end{array}$ \\
\hline Direct effect, $c^{\prime}$ & $\begin{array}{c}-1.913 \\
(0.619) *\end{array}$ & $\begin{array}{c}-3.128 \text { to } \\
-0.698\end{array}$ & $\begin{array}{c}-1.941 \\
(0.618) *\end{array}$ & $\begin{array}{c}-3.153 \text { to } \\
-0.729\end{array}$ & $\begin{array}{l}-2.039 \\
(0.617) *\end{array}$ & $\begin{array}{c}-3.249 \text { to } \\
-0.829\end{array}$ \\
\hline Indirect effect, ab & $\begin{array}{l}-0.757 \\
(0.168)\end{array}$ & $\begin{array}{c}-1.104 \text { to } \\
-0.453\end{array}$ & $\begin{array}{l}-0.387 \\
(0.135)\end{array}$ & $\begin{array}{l}-0.672 \text { to } \\
-0.145\end{array}$ & $\begin{array}{l}-0.282 \\
(0.107)\end{array}$ & $\begin{array}{c}-0.517 \text { to } \\
-0.095\end{array}$ \\
\hline $\begin{array}{l}\text { Ratio of indirect to total } \\
\text { effect mediated (\%) }\end{array}$ & 28.4 & & 16.1 & & 12.1 & \\
\hline Sobel test & $-4.632 * *$ & & $-3.004^{* *}$ & & $-2.753^{* *}$ & \\
\hline
\end{tabular}

\section{Discussion}

In this study, we examined the mediating effect of eCRF on the relationships between comorbidities and HRQoL in older Korean adults with diabetes. Our findings show that both comorbidities and eCRF are important predictors of HRQoL among older Korean patients. This is the first study to report that eCRF mediates the impact of comorbidities on HRQoL partially and independently among patients with diabetes.

The current findings agree with previous studies reporting an inverse relationship between comorbidities and HRQoL in patients with diabetes. For example, Wexler et al. [21] examined the impacts of medical comorbidities and depression on HRQoL in a large primary care cohort of patients with type 2 diabetes and showed that treatment of depression and prevention of complications were important determinants of HRQoL. By analyzing the treatment options for type 2 diabetes in adolescents and youth (TODAY) study data, Larkin et al. [22] showed that HRQoL was negatively associated with depressive symptoms and number of comorbidities in youth with type 2 diabetes. This inverse relationship between HRQoL and comorbidities has also been observed in patients with chronic conditions [23], dementia [24], psoriatic arthritis [25], and survivors of breast [26] and colorectal cancer [27].

Likewise, the current findings are consistent with previous studies reporting a positive relationship between CRF and HRQoL in patients with type 2 diabetes [28], pediatric patients with type 1 diabetes [29], and women at risk of gestational diabetes [30]. Using patient records from the 2002 to 2012 Calidad de Vida Center, Clennin et al. [11] examined the relationship between CRF and HRQoL in a Uruguayan cohort at risk for developing cardiovascular disease (CVD) and found positive associations between CRF and several dimensions of HRQoL (women: vitality, physical health, physical role, bodily pain, and general health; men: physical health). In children and adolescents with type 1 diabetes, Lukács et al. [31] examined associations among HRQoL, clinical profiles, anthropometric measures, and physical activity and CRF and found that good CRF was significantly associated with better HRQoL and favorable metabolic control among the youth. Similarly, this positive association between CRF and HRQoL was observed in community-dwelling older adults [32] and workers [33], as well as in patients with CVD [11], McArdle disease [34], severe mental illness [35], and survivors of cancer [36]. 
Our study is the first to extend these findings to show that CRF may mediate the impact of comorbidities on HRQoL in patients with diabetes. The mediating effect of eCRF on the relationship between comorbidities and HRQoL was independent of potential covariates, including demographics (age, sex, marital status), SES (income and education), health behaviors (smoking, alcohol consumption, and regular exercise) and depressive symptoms. In support of the current findings, the findings of the FIT study involving 46,979 patients showed that achieving $\geq 12$ METs reduced the incidence of diabetes compared to achieving $<6$ METs in both non-obese (hazard ratio $=0.73 ; 95 \% \mathrm{CI}=0.59-0.91$; $p<0.001$ ) and obese individuals (hazard ratio $=0.56 ; 95 \%$ CI $0.42-0.73 ; p<0.001$ ) $[37,38]$. In that study [37], the protective effect of achieving high CRF was found to be independent of a number of confounders, including age, sex, race, BMI, history of hypertension, hypertension medication use, ACE inhibitor use, angiotensin II receptor blocker use, b-blocker use, diuretic use, history of hyperlipidemia, lipid lowering medication use, statin use, history of obesity, family history of coronary heart disease, current smoking status, sedentary lifestyle, treated pulmonary disease, depression medication use, and indication for stress testing. Taken together, those findings suggest that high CRF may alleviate the impact of comorbidities on HRQoL in patients with diabetes. Thus, promotion of CRF in conjunction with management of comorbidities targeted at increasing HRQoL should be a key component of the overall management of such patients.

HRQoL worsens as the number of diabetes-related comorbidities increases [21]. Thus, information regarding determinants and/or mediators of HRQoL is essential for development and implementation of an effective care program to promote physical and mental well-being for older patients with diabetes. Higher levels of physical activity and fitness are associated with lower risks of morbidity and mortality in healthy adults and patients with chronic diseases. Higher CRF is also associated with better HRQoL in healthy adults and in patients with chronic disease.

The current study has some limitations. First, the cross-sectional study design does not allow causal inference regarding the relationships among comorbidities, eCRF, and HRQoL. A randomized controlled trial on exercise training would be necessary to confirm the mediating effect of CRF on the relationship between comorbidities and HRQoL in a cause-and-effect manner. Second, several potential mediators such as sex, SES, depression, and social networking were identified in previous studies [29]. A more complex mediation model or examination of a larger number of mediation variables should help elucidate the roles of mediator(s) in determining the relationships between exposure and outcomes. Third, the questionnaire of the survey used in this study was not designed to identify the type of diabetes, which should be addressed in a future study. Lastly, a further study will be necessary to investigate the mechanism(s) through which CRF mediates the relationship between comorbidities and HRQoL in diabetes.

\section{Conclusions}

In summary, our findings indicate the mediating effect of eCRF on the relationship between comorbidities and HRQoL in older Korean adults with diabetes. Assessment of eCRF should be considered an important measure for evaluating the overall management of diabetes. From a public health perspective, these findings could help guide public agencies when developing future healthcare policies to promote health equality for geriatric patients with diabetes in South Korea.

Author Contributions: Conceptualization, I.L. and H.K.; Methodology, I.L., S.K. and H.K.; Formal Analysis, I.L., S.K. and H.K.; Investigation, I.L., S.K. and H.K.; Writing-Original Draft Preparation, I.L. and H.K.; Writing-Review \& Editing, I.L. and H.K.; Funding Acquisition, National Research Foundation (NRF), S.K. All authors have read and agreed to the published version of the manuscript.

Funding: This study was supported by the National Research Foundation Grant funded by the Korean Government (NRF-2017R1A2B4010684).

Acknowledgments: The authors thank to Kelly O'Keefe (English editor) and anonymous Reviewers who allowed us to improve the manuscript.

Conflicts of Interest: The authors declare no conflict of interest. 


\section{References}

1. Saito, I.; Inami, F.; Ikebe, T.; Moriwaki, C.; Tsubakimoto, A.; Yonemasu, K.; Ozawa, H. Impact of diabetes on health-related quality of life in a population study in Japan. Diabetes Res. Clin. Pract. 2006, 73, 51-57. [CrossRef]

2. Eisele, M.; Kaduszkiewicz, H.; König, H.H.; Lange, C.; Wiese, B.; Prokein, J.; Weyerer, S.; Werle, J.; Riedel-Heller, S.G.; Luppa, M.; et al. AgeCoDe Study Group. Determinants of health-related quality of life in older primary care patients: Results of the longitudinal observational AgeCoDe study. Br. J. Gen. Pract. 2015, 65, e716-e723. [CrossRef]

3. Yancik, R.; Ershler, W.; Satariano, W.; Hazzard, W.; Cohen, H.J.; Ferrucci, L. Report of the national institute on aging task force on comorbidity. J. Gerontol. Biol. Sci. Med. Sci. 2007, 62, 275-280. [CrossRef] [PubMed]

4. Tran, J.; Norton, R.; Conrad, N.; Rahimian, F.; Canoy, D.; Nazarzadeh, M.; Rahimi, K. Patterns and temporal trends of comorbidity among adult patients with incident cardiovascular disease in the UK between 2000 and 2014: A population-based cohort study. PLoS Med. 2018, 15, e1002513. [CrossRef] [PubMed]

5. Mata-Cases, M.; Franch-Nadal, J.; Real, J.; Cedenilla, M.; Mauricio, D. Prevalence and coprevalence of chronic comorbid conditions in patients with type 2 diabetes in Catalonia: A population-based cross-sectional study. BMJ Open 2019, 9, e031281. [CrossRef] [PubMed]

6. Kodama, S.; Saito, K.; Tanaka, S.; Maki, M.; Yachi, Y.; Asumi, M.; Sugawara, A.; Totsuka, K.; Shimano, H.; Ohashi, Y.; et al. Cardiorespiratory fitness as a quantitative predictor of all-cause mortality and cardiovascular events in healthy men and women: A meta-analysis. JAMA 2009, 301, 2024-2035. [CrossRef]

7. Wang, Y.; Chen, S.; Zhang, J.; Zhang, Y.; Ernstsen, L.; Lavie, C.J.; Hooker, S.P.; Chen, Y.; Sui, X. Nonexercise estimated cardiorespiratory fitness and all-cancer mortality: The NHANES III Study. Mayo Clin. Proc. 2018, 93, 848-856. [CrossRef]

8. Ekblom-Bak, E.; Ekblom, B.; Söderling, J.; Börjesson, M.; Blom, V.; Kallings, L.V.; Hemmingsson, E.; Andersson, G.; Wallin, P.; Ekblom, Ö. Sex-and age-specific associations between cardiorespiratory fitness, CVD morbidity and all-cause mortality in 266.109 adults. Prev. Med. 2019, 127, 105799. [CrossRef]

9. Xu, H.; Tang, L.; Hu, Z.; Gao, F.; Yang, Y.; Qin, L.; Luo, B.A. Association between physical activity and health-related quality of life in elderly individuals with pre-diabetes in rural Hunan Province, China: A cross-sectional study. BMJ Open 2018, 8, e019836. [CrossRef]

10. Subramaniam, M.; Zhang, Y.; Lau, J.H.; Vaingankar, J.A.; Abdin, E.; Chong, S.A.; Lee, E.S. Patterns of physical activity and health-related quality of life amongst patients with multimorbidity in a multi-ethnic Asian population. BMC Public Health 2019, 19, 1612. [CrossRef]

11. Clennin, M.N.; Payne, J.P.; Rienzi, E.G.; Lavie, C.J.; Blair, S.N.; Pate, R.R.; Sui, X. Association between cardiorespiratory fitness and health-related quality of life among patients at risk for cardiovascular disease in Uruguay. PLoS ONE 2015, 10, e0123989. [CrossRef] [PubMed]

12. Stamatakis, E.; Hamer, M.; O’Donovan, G.; Batty, G.D.; Kivimaki, M. A non-exercise testing method for estimating cardiorespiratory fitness: Associations with all-cause and cardiovascular mortality in a pooled analysis of eight population-based cohorts. Eur. Heart J. 2013, 34, 750-758. [CrossRef]

13. Jurca, R.; Jackson, A.S.; LaMonte, M.J.; Morrow, J.R., Jr.; Blair, S.N.; Wareham, N.J.; Haskell, W.L.; van Mechelen, W.; Church, T.S.; Jakicic, J.M.; et al. Assessing cardiorespiratory fitness without performing exercise testing. Am. J. Prev. Med. 2005, 29, 185-193. [CrossRef]

14. Song, M.; Lee, I.; Kang, H. Cardiorespiratory Fitness without Exercise Testing Can Predict All-Cause Mortality Risk in a Representative Sample of Korean Older Adults. Int. J. Environ. Res. Public Health 2019, 16, 1633. [CrossRef] [PubMed]

15. Won, J.C.; Lee, J.H.; Kim, J.H.; Kang, E.S.; Won, K.C.; Kim, D.J.; Lee, M.K. Diabetes fact sheet in Korea, 2016: An appraisal of current status. Diabetes Metab. J. 2018, 42, 415-424. [CrossRef]

16. Kweon, A.; Kim, Y.; Jang, M.-J.; Kim, Y.; Kim, K.; Choi, S.; Chun, C.; Khang, Y.-H.; Oh, K. Data resource profile: The Korea National Health and Nutrition Examination Survey (KNHANES). Int. J. Epidemiol. 2014, 43, 69-77. [CrossRef] [PubMed]

17. Choi, Y.J.; Lee, M.S.; An, S.Y.; Kim, T.H.; Han, S.J.; Kim, H.J.; Chung, Y.S.; Lee, K.W.; Kim, D.J. The relationship between diabetes mellitus and health-related quality of life in Korean adults: The fourth Korea National Health and Nutrition Examination Survey (2007-2009). Diabetes Metab. J. 2011, 35, 587-594. [CrossRef] [PubMed] 
18. The EuroQol Group. EuroQol-A new facility for the measurement of health-related quality of life. Health Policy 1990, 16, 199-208. [CrossRef]

19. Brooks, R. EuroQol: The current state of play. Health Policy 1996, 37, 53-72. [CrossRef]

20. Baron, R.M.; Kenny, D.A. The moderator-mediator variable distinction in social psychological research: Conceptual, strategic, and statistical considerations. J. Personal. Soc. Psychol. 1986, 51, 1173-1182. [CrossRef]

21. Wexler, D.J.; Grant, R.W.; Wittenberg, E.; Bosch, J.L.; Cagliero, E.; Delahanty, L.; Blais, M.A.; Meigs, J.B. Correlates of health-related quality of life in Type 2 diabetes. Diabetologia 2006, 49, 1489-1497. [CrossRef] [PubMed]

22. Larkin, M.E.; Walders-Abramson, N.; Hirst, K.; Keady, J.; Ievers-Landis, C.E.; Venditti, E.M.; Yasuda, P.M. Effects of comorbid conditions on health-related quality of life in youth with Type 2 diabetes: The TODAY clinical trial. Diabetes Manag. 2015, 5, 431-439. [CrossRef] [PubMed]

23. Hutchinson, A.F.; Graco, M.; Rasekaba, T.M.; Parikh, S.; Berlowitz, D.J.; Lim, W.K. Relationship between health-related quality of life, comorbidities and acute health care utilization in adults with chronic conditions. Health Qual. Life Outcomes 2015, 13, 39. [CrossRef] [PubMed]

24. Nelis, S.M.; Wu, Y.T.; Matthews, F.E.; Martyr, A.; Quinn, C.; Rippon, I.; Rusted, J.; Thom, J.M.; Kopelman, M.D.; Hindle, J.V.; et al. The impact of co-morbidity on the quality of life of people with dementia: Findings from the IDEAL study. Age Aging 2019, 48, 361-367. [CrossRef]

25. Bavière, W.; Deprez, X.; Houvenagel, E.; Philippe, P.; Deken, V.; Flipo, R.M.; Paccou, J. Association between Comorbidities and Quality of Life in Psoriatic Arthritis: Results from a Multicentric Cross-sectional Study (PSAQUAL study). J. Rheumatol. 2019. [CrossRef]

26. Lim, J.W. The impact of comorbidity on the relationship between life stress and health-related quality of life for Chinese- and Korean-American breast cancer survivors. Ethn. Health 2018, 23, 16-32. [CrossRef]

27. Wang, J.W.; Sun, L.; Ding, N.; Li, J.; Gong, X.H.; Chen, X.F.; Yu, D.H.; Luo, Z.N.; Yuan, Z.P.; Yu, J.M. The association between comorbidities and the quality of life among colorectal cancer survivors in the People's Republic of China. Patient Prefer. Adher. 2016, 10, 1071-1077. [CrossRef]

28. Bennett, W.L.; Ouyang, P.; Wu, A.W.; Barone, B.B.; Stewart, K.J. Fatness and fitness: How do they influence health-related quality of life in type 2 diabetes mellitus? Health Qual. Life Outcomes 2008, 6, 110. [CrossRef]

29. Lukács, A.; Varga, B.; Kiss-Tóth, E.; Soós, A.; Barkai, L. Factors influencing the diabetes-specific health-related quality of life in children and adolescents with type 1 diabetes mellitus. J. Child Health Care 2014, 18, 253-260. [CrossRef]

30. Engberg, E.; Tikkanen, H.O.; Koponen, A.; Hägglund, H.; Kukkonen-Harjula, K.; Tiitinen, A.; Peltonen, J.E.; Pöyhönen-Alho, M. Cardiorespiratory fitness and health-related quality of life in women at risk for gestational diabetes. Scand. J. Med. Sci. Sports 2018, 28, 203-211. [CrossRef] [PubMed]

31. Lukács, A.; Mayer, K.; Török, A.; Kiss-Tóth, E.; Barkai, L. Better cardiorespiratory fitness associated with favorable metabolic control and health-related quality of life in youths with type 1 diabetes. Acta Physiol. Hung. 2013, 100, 77-83. [CrossRef] [PubMed]

32. Wanderley, F.A.C.; Silva, G.; Marques, E.; Oliveira, J.; Mota, J.; Carvalho, J. Associations between objectively assessed physical activity levels and fitness and self-reported health-related quality of life in community-dwelling older adults. Qual. Life Res. 2011, 20, 1371-1378. [CrossRef] [PubMed]

33. Strijk, J.E.; Proper, K.I.; Klaver, L.; van der Beek, A.J.; van Mechelen, W. Associations between VO2max and vitality in older workers: A cross-sectional study. BMC Public Health 2010, 1, 684. [CrossRef]

34. Mugui’a-Izquierdo, D.; Santalla, A.; Lucia, A. Cardiorespiratory Fitness, Physical Activity, and Quality of Life in Patients with McArdle Disease. Med. Sci. Sports Exerc. 2015, 47, 799-808. [CrossRef] [PubMed]

35. Perez-Cruzado, D.; Cuesta-Vargas, A.I.; Vera-Garcia, E.; Mayoral-Cleries, F. The relationship between quality of life and physical fitness in people with severe mental illness. Health Qual. Life Outcomes 2018, 16, 82. [CrossRef] [PubMed]

36. Buffart, L.M.; De Backer, I.C.; Schep, G.; Vreugdenhil, A.; Brug, J.; Chinapaw, M.J. Fatigue mediates the relationship between physical fitness and quality of life in cancer survivors. J. Sci. Med. Sport 2013, 16, 99-104. [CrossRef] 
37. Juraschek, S.P.; Blaha, M.J.; Al-Mallah, M.H. Response to comment on Juraschek et al. cardiorespiratory fitness and incident diabetes: The FIT (Henry Ford ExercIse Testing) project. Diabetes Care 2015, 38, e194-e195. [CrossRef]

38. Juraschek, S.P.; Blaha, M.J.; Blumenthal, R.S.; Brawner, C.; Qureshi, W.; Keteyian, S.J.; Schairer, J.; Ehrman, J.K.; Al-Mallah, M.H. Cardiorespiratory fitness and incident diabetes: The FIT (Henry Ford ExercIse Testing) project. Diabetes Care 2015, 38, 1075-1081. [CrossRef]

(C) 2020 by the authors. Licensee MDPI, Basel, Switzerland. This article is an open access article distributed under the terms and conditions of the Creative Commons Attribution (CC BY) license (http://creativecommons.org/licenses/by/4.0/). 